\title{
Perceptions of orphans' grief support program in Zambia
}

\author{
Sharon M. Kirkpatrick ${ }^{1}$, Beverly J. South ${ }^{2}$, Wilaiporn Rojjanasrirat ${ }^{2}$, Kelsey Welch Novelli ${ }^{3}$, Lee A. \\ Williams ${ }^{2}$ \\ 1. HealthEd Connect, MO, U.S.A. 2. Graceland University, MO, U.S.A. 3. University Medical Center -Brackenridge, Austin, \\ TX, U.S.A.
}

Correspondence: Sharon M. Kirkpatrick. Address: HealthEd Connect, 1401 West Truman Road, Independence, MO 64050, U.S.A. Email: skirkpatrick@healthedconnect.org

Received: April 30, 2014

DOI : $10.5430 /$ cns.v2n4p30

Online Published: July 27, 2014

Accepted: July 23, 2014

URL: http://dx.doi.org/10.5430/cns.v2n4p30

\section{Abstract}

Purpose: To describe the perceptions of orphans, their caregivers, and teachers related to the implementation of grief support intervention programs.

Methods: A descriptive study using structured interview questionnaires was conducted among 74 participants, which included 32 orphans, 32 caregivers, and 10 teachers in the Copperbelt Province of Zambia.

Findings: Small-group interventions alleviated some of the manifestations of grief in the orphans who participated. They reported feeling happier, less lonely, less angry and more confident. Caregivers and teachers perceived positive changes in orphans' behavior.

Conclusions: Orphans benefit from small-group grief support interventions. On-going evaluation of activities and interventions is essential to enhance the effectiveness of grief support programs.

Clinical relevance: Healthcare professionals play a key role in developing, evaluating, and promoting programs which address the emotional distress of grieving orphans.

\section{Key words}

Grief, Orphans, Support Groups, Zambia

\section{Introduction}

Over 1.3 million orphans live in the AIDS-stricken country of Zambia ${ }^{[1]}$. Emotional needs frequently go unmet, and orphans are at risk of depression, delinquency, conduct problems, stigmatization, and post-traumatic stress disorder (PTSD) ${ }^{[2-4]}$. Previous research assessing orphans' emotional distress in Zambia found evidence of anger, worry, sadness, and social isolation indicating a need for intervention ${ }^{[5]}$.

Zambia, one of the world's poorest countries, struggles to provide even basic material necessities such as food and clothing for these children ${ }^{[6]}$. In the Copperbelt Province, poverty is especially acute. Located in sub-Sahara Africa, the country is rich in cultural traditions with over 70 languages and dialects ${ }^{[7]}$. Once a thriving industrial area due to rich 
copper mines, the Province fell into acute poverty when the copper industry collapsed in the $90 \mathrm{~s}^{[8]}$. The trucking industry which supported the mining operations also provided the vehicle for the rapid spread of acquired immunodeficiency syndrome (AIDS) as men traveled from town to town and engaged in sex with multiple partners. Ultimately, children became orphaned and parentless households began to emerge with sibling, extended family, or elderly grandmother caregivers.

\subsection{Background}

While children's emotional distress related to death has been well-documented in numerous studies, there is a paucity of published evidence-based interventions. A Cochrane Collaboration review ${ }^{[9]}$ found numerous qualitative, descriptive and anecdotal studies related to emotional distress. According to these authors, none of the studies offered high-quality evidence of interventions that could be applied with confidence to improve the psychosocial well-being of orphans who have experienced the death of those closest to them. A review by Sherr and Mueller ${ }^{[10]}$ pointed to a similar problem with anecdotal and single-intervention strategy evidence.

Quasi-experimental and mixed method intervention studies have employed peer-group support with significant improvements in anxiety levels, depression, and anger among adolescent AIDS orphans ${ }^{[11]}$. Williams ${ }^{[12]}$ utilized teaching and images for imparting culturally appropriate concepts relating to death and loss in workshops for orphans in Mongu, Zambia. The theoretical orientation of Williams' ${ }^{[12]}$ grief-support program was based on Bowlby's Theory of Attachment ${ }^{[13]}$. According to this theory, the kinship bond between children and their parents form the "glue" that anchors children. When this bond is broken through death, children may experience adverse reactions ${ }^{[14]}$. Williams discovered challenges with caregivers, teachers, and guardians who were eager to help grieving children, but initially were not comfortable facilitating workshops about grief and death. These observations from Williams ${ }^{[12]}$ and Kumakech ${ }^{[11]}$, provided guidance for developing and implementing strategies for the orphans in this study.

\subsection{Beliefs about death and children}

The central purpose of Leininger's theory, Culture Care, Diversity, and Universality, is to "discover and explain diverse and universal culturally based care factors influencing the health, well-being, illness, or death of individuals or groups” [15] Application of Leininger's theory provided guidance in this study for pursuing a broader perspective on Zambian cultural beliefs and practices regarding death and the ways this impacts children's grief processes. Interviews of demographically representative community leaders were conducted using "Zambian Beliefs about Death Impacting Children Survey Questions” (see Table 1). Responses to the five open-ended questions provided insights on how death is celebrated and mourned according to the family's religious beliefs and the cultural practices of their community.

Table 1. Survey questions relating to zambian beliefs about death

1) Describe how Zambians typically deal with death of a family member and handle grief.

2) What does death mean to the children? How are children told about death?

3) How do children usually come to understand about parent's death?

4) How does food or music play a special traditional role following a death in the family?

5) Have traditions related to death changed during your lifetime? If so, how?

Community members' responses from the interviews relating to Zambian beliefs about death noted that children are often "protected" from participating in funerals or learning of the death of a loved one for fear of instilling fear. In the past, children were sometimes hidden in homes until after the deceased was buried. Children were typically told the parent had "gone away" and not told of the death unless they specifically asked. If it was believed the child was old enough to understand the concept of death, the child was told the parent died and went to heaven. These findings are consistent with the findings of Williams ${ }^{[12]}$ who suggested there is "a lack of knowledge and comfort in helping children cope with death (i.e., how and when children should be told about the death of a loved one, and when they should be involved in funeral and memorial planning)". A study by Family Health International evaluated psychosocial factors when orphans received 
support from a person trained to provide emotional support to OVC's and concluded "that training a small number of carefully selected community cadres to respond to psychosocial issues faced by orphans and vulnerable children has a rippling effect on the community" ${ }^{[12]}$.

\subsection{Purpose}

This qualitative study described perceptions of orphans and vulnerable children, their caregivers, and teachers regarding the implementation of grief support intervention programs. The study addressed the following questions: What are the orphans' perceptions regarding the impact of the interventions on their emotional distress? What are the caregivers' perceptions of the impact of the interventions on the emotional distress of the orphan? What are the teachers' perceptions of the impact of the interventions on the emotional distress of the orphans? Persons interviewed in all three groups named specific changes as evidence of the impact of the interventions. The teachers also provided an evaluation of the changes they observed in the children.

\section{Methods}

\subsection{Child support specialist (CSS) training}

Volunteer Kafwa (Chibemba for helpers) have served their communities for over twenty years by monitoring babies, teaching mothers, and providing home-based care. As the human immunodeficiency virus (HIV) spread and parents died of AIDS, the Kafwa became increasingly concerned about grieving orphans in their communities. The Kafwa were eager to help the orphans but had no experience or training in grief counseling. In response to their request for assistance, a United States (U.S.) team composed of a university professor, a community health nurse, and a social worker with expertise in pediatric grieving, collaborated to develop a week-long training session called "Children Cry: We Respond".

The training, held in Chipulukusu in January 2011, consisted of seven modules, adapted from Rankin ${ }^{[16]}$ and Pines ${ }^{[14]}$, designed to prepare the Kafwa to become group facilitators known locally as Child Support Specialists (CSS). Kafwa from Chipulukusu, Kasompe and Zamtan in the Copperbelt Province attended the training. Training materials were provided with dual English and Chibemba (predominant local language) translations.

The training sessions were lively and emotional with the thirty Kafwa attendees sharing, many for the first time, their own stories of grief and loss. Strategies for identifying children's developmental stages related to the processing of grief were presented through role play and creative activities. The training workshop culminated with an exercise in which the Kafwa identified ways to organize and facilitate groups, including the obtainment of referrals from teachers and permission for a child's participation from caregivers.

\subsection{Description of I subilo support groups}

At the conclusion of the CSS training, support groups named Isubilo (hope in Chibemba), were organized to initiate the intervention. Each Isubilo group met after school for two-hour age-appropriate sessions. The groups in Kasompe met twice weekly for six and a half weeks while the groups in Zamtan and Chipulukusu met weekly for 13 weeks.

Support groups were chosen for the intervention because of their documented effectiveness in promoting positive change in diverse settings. Some therapeutic factors such as group cohesiveness were identified as preconditions to change while others were related to subsequent changes in cognition and behavior ${ }^{[17]}$. The Isubilo support group format was adapted from Healing Connections: A Grief Support Program for Children ${ }^{[14]}$. The objectives were intended to help each child (1) accept the reality of the loss and realize that the person would not return; (2) express his or her emotional pain either verbally or in other ways such as drama or art; (3) adjust to the new reality of an environment in which the loved one is missing; and (4) relocate the dead person within the child's life from a living presence to a memory. 
Support group activities were adapted from Playing through Grief: Interventions for kids ${ }^{[18]}$. Opening activities included ice breakers to develop welcoming relationships within the group. Sessions began with lighting a candle and ended with forming a circle, passing a squeeze, and saying chibote (peace in Chibemba). Webb ${ }^{[19]}$ found activities such as these important since children process grief through play and need an environment where they feel comfortable. Activities designed to help the children accept the reality of loss included a nature walk to identify live and dead objects and the reading of excerpts from Water Bugs and Dragonflies: Explaining death to young children ${ }^{[20]}$.

Helping the children express emotional pain was accomplished through dancing, drawing, and playing games. Activities to help the children adjust to a new reality included reading excerpts from Tree of Life: The Incredible Biodiversity of Life on Earth ${ }^{[21]}$, and identifying life-death cycles in nature. Memory and relocating were accomplished by having the children describe and draw pictures of their deceased loved one in memory books, as well as make paper-bead bracelets with messages to their loved one inscribed inside the beads. Lowenstein found that mementos of a deceased loved one play an important role in providing ongoing, tangible connectedness to the child ${ }^{[22]}$.

The final session focused on the reality and finality of death. Culminating activities included having the children describe a memory of their loved one, identifying the best part of being in the group, sharing group memories, and making a friendship paper chain. Throughout the sessions, orphans who participated in the support groups received small gifts such as biscuits, soap or craft items. The Isubilo support groups were evaluated using interviews to assess the perceptions of the orphans, caregivers and teachers.

\subsection{Setting and sample}

A descriptive study was conducted in the communities of Chipulukusu, Kasompe, and Zamtan in June, 2012 following training of the facilitators and implementation of the program. These communities are primarily composed of small, crude-brick homes with tin roofs and dirt or cement floors. Inclusion criteria for the study consisted of preschool and school-age orphans, their caregivers and their community school teachers. Orphans were defined as children for whom one or both parents were deceased. The caregiver was defined as living in the same household as the orphan and having primary responsibility for the child. The community school teachers involved in this study observed one or more of the orphan participants in their classrooms.

The CSS had personally identified orphans in their immediate neighborhoods whom they believed would benefit from the group. In addition, school teachers referred orphans in their classes who cried frequently, appeared to have no friends, and did not participate in class discussions. The CSS visited the homes of the identified orphans to explain the program to the caregivers and obtain permission for the child to attend the group. Children were divided by age into two support groups of eight to twelve children each.

\subsection{Data collection}

Following Graceland University Institutional Review Board approval, field interviews were organized by four World Service Corps (WSC) volunteers who were sponsored by a faith-based organization (two from Zambia who spoke Chibemba and two from the U.S. who spoke English). The CSS conducted the interviews and the WSC volunteers verified and recorded the answers.

A total of eighty-five structured interviews were conducted. Thirty-two kindergarten and primary school children, 17 boys and 15 girls, participated in face-to-face interviews. The children reported ages ranging from 4 to 16 years. The ages of the children were not verified, however, since birth certificates are rare and birthdates are frequently not known. The 16-year-old orphans were older than might usually be expected in primary school since it is common in Zambia for older children to be in lower grades due to a lack of earlier opportunities. 
The interview guide adhered to Leininger's theory by using open-ended questions related to universally accepted support group benefits as well as culturally based factors identified by the participants. The children's interviews were composed of eight open-ended questions designed to determine if changes had occurred in their emotional distress as a result of participation in the Isubilo groups. Children were also asked to identify the activities deemed most and least helpful. Thirty-one caregivers, consisting of widowed mothers, grandmothers, and other extended family members, were interviewed face-to-face using five open-ended questions to assess their perception of changes in the children subsequent to the interventions. Ten teachers completed twenty-two interviews containing five open-ended questions regarding behavioral differences observed in students who had participated in the interventions. The teachers each spoke fluent English and chose to answer the questionnaires in writing rather than verbally.

\subsection{Data analysis}

Qualitative data obtained from interviews were analyzed using content analysis. All four investigators analyzed data independently by reading the documented forms for contextual meanings and pattern. Data were then identified, extracted, coded, categorized into major themes and noted as to number of times mentioned. Charts and a matrix were developed for organizing codes and categories from each participant data file. This matrix brought together substantive information from each participant to enhance the content analysis interpretations ${ }^{[23]}$. Quotations and short summary phrases were used to present concepts from each of the three identified themes: behavioral changes, emotional changes, and spiritual benefits. Examples of tangible benefits were also named by some of the participants even though the questionnaire did not attempt to elicit this information.

Table 2. Changes identified by orphans post-support group participation

\begin{tabular}{ll}
\hline Behavioral Changes & Able to play without fighting \\
& More mindful and respectful at home \\
& Increased attentiveness with completing chores and schoolwork \\
& Increased interest in school activities \\
& Increased socialization \\
& Less crying \\
& Happier \\
Emotional Changes & Less anger and resentment \\
& Less lonely \\
& More confident \\
& Feels deserving of happiness \\
& Helpful with morality and spirituality \\
Spiritual Changes & A return to church \\
& Realizing God loves us \\
& Loving self and others \\
\hline
\end{tabular}

\section{Results}

Recurrent themes of behavioral and emotional changes noted by the orphans, caregivers, and teachers provided evidence the Isubilo were successful in meeting needs of the participating orphans (see Table 2). When asked, "Has the support group been helpful to you?" All but one of the respondents answered, "Yes" and the child who responded "No" said she had been happy before the intervention and continued to be happy. Positive responses given by the orphans were affirmed by the caregivers and teachers. Even though there were no specific questions regarding spiritual, educational, or tangible assistance, both caregivers and orphans mentioned these as benefits from the program. Spiritual benefits included moral guidance and awareness that there was a God that loved them. Specific tangible benefits included snacks provided during the support groups as well as items of used clothing. Education included information shared in the CSS groups as well as formal education in local community schools. The clothing and formal educational opportunities were provided 
independent of the support groups but were perceived as being one and the same since several teachers and health workers were involved in both the Isubilo groups and community schools.

\subsection{Behavioral changes}

Behavioral changes were defined as modifications in how the children conducted themselves after participating in the support groups (see Table 2). One of the behavioral changes identified by the children included an increase in positive interactions with others. One child commented, "I learned how to play without fighting and to be happy." This change was also noted by a teacher who wrote, " but now upon attending the CSS sessions, she has changed a bit because she can now play with other students and she is not [sic] longer fighting with anyone.” Caregivers wrote that the orphans were more mindful and respectful at home and completed their chores and schoolwork in a timely manner.

The teachers noted in their responses that overall the children became more attentive in class, showed increased interest in school activities, were more respectful and had increased socialization. One teacher observed of a student, " ever since she started attending CSS sessions she has completely changed. She now has interest in all the school work and whenever I am teaching she's now concentrating. Now she is asking questions whenever and wherever she is not clear...” One teacher noted, "He was really lonely; he didn’t want to interact with his fellow students. While he was attending CSS sessions I noticed that he changes [sic] from being lonely to socializing with his fellow students." Another teacher wrote, one student " has changed since he started learning with the CSS group because he has started speaking in class and playing with his friends more.” However, the same teacher commented, another child " has not had much change. She still cries sometimes in class and she needs more help."

\subsection{Emotional changes}

Emotional changes were defined as those instinctive feelings independent from reasoning or logic. Responses by orphans provided evidence that they were happier, less lonely, less angry, and more confident after attending the Isubilo support groups (see Figure 1). One orphan said the thing she liked best was "learning how to cope with sadness and be happy." Another responded that she felt better able to share her problems with others and had stopped thinking about death so often. A 13-year-old male reported, "When my father died, I lost confidence and was always sad but when I joined the group they boosted my esteem and happiness." When asked what they learned in the group, one child responded, "that I am human and deserve some happiness.”

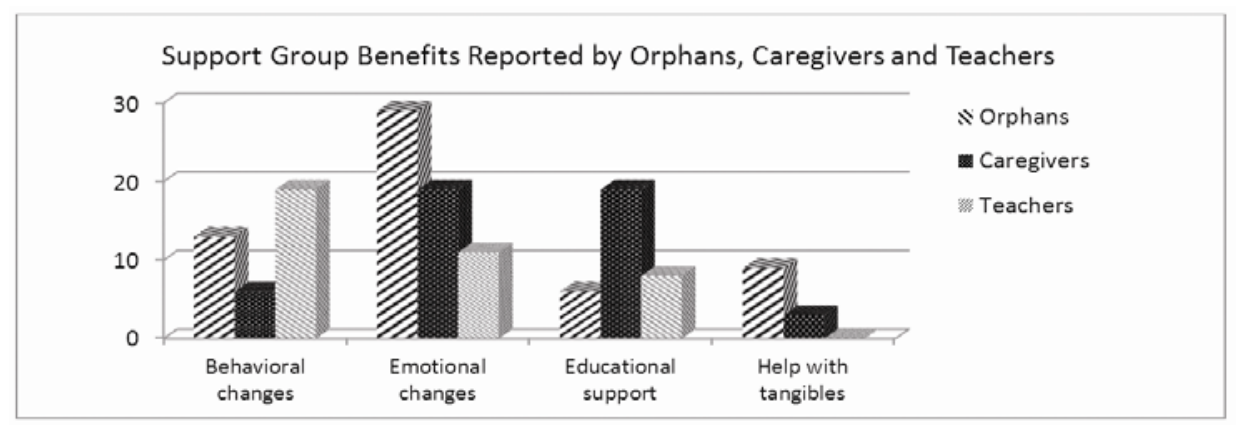

Figure 1. Support group benefits reported by orphans, caregivers and teachers

Changes identified by the orphans were echoed by teachers. One teacher said "the program has made the child realize she is not alone" and another noted, "the program has enabled this child to deal with resilience." Although caregivers were able to identify behavioral changes in the orphans, they did not report observing emotional changes. 


\subsection{Spiritual benefits}

Qualitative data collection reflected an additional theme of spiritual benefits for children who participated in the support groups (see Table 2). Spiritual changes were defined as religious beliefs or moral values. While spiritual changes were not part of the original data set to be assessed, the common thread of these changes in this community's responses appeared several times and were categorized based on their relation to values or religious beliefs. Specific spiritual benefits identified included feeling loved by God, developing good morals, and Bible teachings. One OVC said he was comforted because he now knew God loved him and he should also love others. A caregiver expressed appreciation for the spiritual support offered in Isubilo while a teacher noted the support groups "helped to change the child's morality."

\subsection{Program evaluation by participants}

All orphans, caregivers and teachers were satisfied with the support groups with few exceptions. When asked, "Do you think other children would benefit from the support group?" all of the participants responded, "Yes." When the children were asked what they liked least about the groups, all but two of the orphans responded, "Nothing" and most added that they liked everything about the groups. Of the children who had a negative reply, one responded that they did not like the "eating" and another reported they did not like "the drawing." One caregiver indicated trust had been broken between her and her child because "someone told him they (his parents) were dead before I could explain." All teachers indicated they liked everything about Isubilo groups while at the same time made numerous suggestions for expansion of the program. One said she felt groups should meet more frequently and that all children should be included, not only the orphans, "because it is so helpful." Another requested that food be served to the children on the days they attended the support groups. Four teachers expressed disappointment that home visits by the CSS were not conducted as frequently as they had expected.

\section{Discussion}

This study described the participants' perceptions regarding the effectiveness of small group interventions in alleviating some manifestations of grief in orphans. A high level of satisfaction with the program was expressed by all participants. Positive changes in the orphans were verified through interviews with the caregivers, teachers, and children themselves. The orphans reported a greater measure of personal happiness and overwhelmingly agreed that other children would benefit from participating in future support groups. Teachers noticed increased sociability, ability to concentrate, and greater participation in school activities among the children who participated. The caregivers confirmed these changes and also voiced appreciation for the educational component of the Isubilo (see Figure 1).

Needs assessments from an initial study ${ }^{[5]}$ provided a basis for understanding the specific problems and needs of caregivers and orphans. The interviews with community leaders gave the investigators a broader understanding of the beliefs and practices regarding death, providing a sound foundation for program development. Community health workers specifically trained as Child Support Specialists supplied critical leadership for program implementation and data collection.

The strengths of this study include:

- the use of developmentally and culturally sensitive materials

- a grief support intervention program delivered by trained Child Support Specialists

- data collection by a culturally competent team who spoke the local language

- data triangulation using perceptions from multiple perspectives 
Ongoing positive feedback from the orphans expressing appreciation for the interventions encourages the volunteer CSS to continue their efforts. The CSS facilitators take turns leading groups which lessens the demands on any one volunteer. Even though the sessions were designed to use activities with little or no cost, such as nature walks and games, the addition of refreshments, craft items, and occasional gifts of used clothing enhance the experience.

Based on these findings, studies with larger samples and appropriate comparison groups using standardized instruments with longitudinal follow-ups are needed. Behavioral and emotional changes of individual orphans should be assessed in relationship to living conditions and their caregiver/child relationship.

\section{Conclusion}

Findings from this study provide a solid foundation for further research related to grief support interventions for orphans in Zambia. This research provides evidence that orphans perceive a significant decrease in emotional distress as a result of the support group interventions employed in this study. Leininger's theory should be adhered to in identifying and explaining the diverse as well as universal culturally-based factors influencing the well-being of Zambian children experiencing grief. Further evaluation is essential to enhance effectiveness of future grief support programs.

Health care professionals are critically needed to provide training and mentoring for volunteer lay workers such as Child Support Specialists. Nurses should foster collaborative relationships with colleagues who face the daunting task of addressing the needs of millions of orphans and vulnerable children in their midst. The expertise and knowledge of professionals is essential for the development, evaluation and revision of interventions.

There is a critical need to develop sustainable, effective and reproducible models to address the emotional distress of grieving orphans. The implications for meeting this need are urgent and far-reaching since these children will soon enter adulthood and have an ever-increasing impact in their communities and countries. Prototypes such as this study should be replicated and expanded to reach a larger segment of the orphan population.

\section{Acknowledgements}

The authors wish to acknowledge the volunteer child support specialists who conducted the interviews, as well as the caregivers, teachers and OVC who willingly shared their stories. Appreciation is also extended to World Service Corps volunteers, who supervised the interviews, and to Dr. Nancy Crigger, who provided valuable suggestions in the writing of the article. Funding for training and assessment was provided by HealthEd Connect.

\section{References}

[1] United Nations Children’s Fund [Internet]. Zambia: Statistics. 2011. Available from: http://www.unicef.org/infobycountry/zambia_statistics.html

[2] Cluver L, Gardner F. Risk and protective factors for psychological well-being of children orphaned by AIDS in Cape Town: A qualitative study of children and caregivers’ perspectives. AIDS Care. 2007; 19(3): 318-325. PMid:17453564 http://dx.doi.org/10.1080/09540120600986578

[3] Cluver L, Gardner F, Operario D. Psychological distress amongst AIDS-orphaned children in urban South Africa. Journal of Child Psychology and Psychiatry. 2007; 48(8): 755-763. PMid:17683447 http://dx.doi.org/10.1111/j.1469-7610.2007.01757.x

[4] Cluver L, Gardner F, Operario D. Effects of stigma on the mental health of adolescents orphaned by AIDS. Journal of Adolescent Health. 2008; 42: 410-417. PMid:18346667 http://dx.doi.org/10.1016/j.jadohealth.2007.09.022

[5] Kirkpatrick SM, Rojjanasrirat W, South BJ, Sindt JA, Williams LA. Assessment of emotional status of orphans and vulnerable children in Zambia. Journal of Nursing Scholarship. 2012; 44: 194-201. PMid:22554249 http://dx.doi.org/10.1111/j.1547-5069.2012.01447.x

[6] United Nations Children's Fund [Internet]. Zambia: Statistics; 2009. Available from: http://www.unicef.org/infobycountry/zambia_statistics.html 
[7] Zambian languages[Internet]. 2014. Available from: http://www.zambia-advisor.com/zambian-languages.

[8] Zambia Development Agency. Zambia Mining Sector Profile [Internet], June 2013. Available from: http://www.zda.org.zm/sites/default/files/zambia mining sector profile-June 2013־_0.pdf.

[9] King E, De Silva M, Stein A, Patel V. Interventions for improving the psychosocial well-being of children affected by HIV and AIDS. Cochrane Database of Systematic Reviews, Issue 2. Art. No.: CD006733. 2009. PMid:19370650 http://dx.doi.org/10.1002/14651858.CD006733.pub2

[10] Sherr L, Mueller J. Where is the evidence base? Mental health issues surrounding bereavement and HIV in children. Journal of Public Mental Health. 2008; 7(4): 31-39. http://dx.doi.org/10.1108/17465729200800027

[11] Kumakech E, Cantor-Graae E, Maling S, Bajunirwe F. Peer-group support intervention improves the psychosocial well-being of AIDS orphans: Cluster randomized trial. Social Science \& Medicine. 2009; 68: 1038-1043. PMid:19167144 http://dx.doi.org/10.1016/j.socscimed.2008.10.033

[12] Williams SJ. My Story: Implementing a grief and loss program in a remote village in Zambia. Nursing Forum; $2008 ; 43: 223-237$. PMid:19076466 http://dx.doi.org/10.1111/j.1744-6198.2008.00116.x

[13] Bowlby J. A Secure Base: Parent-Child Attachment and Healthy Human Development. London: Routledge; 1988.

[14] Pines E. Healing connections: A grief support program for children. San Antonio, Texas: Women’s Global Connection. 2006 Jan.

[15] Dayer-Berenson L. Cultural competencies for nurses (2nd ed.). Burlington, MA: Jones and Bartlett Learning; 2013.

[16] Rankin J, Cochrane R, Khulakahle. Child Counselling and Training Forum. The Child Within: Connecting with children who have experienced grief and loss. Strategies for Hope Trust, UK. 2008.

[17] Yalom I. The theory and practice of group psychotherapy (4th ed.). New York, NY: Basic Books; 1995.

[18] Ford K, D’Arcy P. Playing through grief: Interventions for kids[Internet]. 2011. Avaible from: http://www.myhealingplace.org/store.htm

[19] Webb N. (editor). Helping bereaved children: A handbook for practitioners. (2nd ed.). New York, NY: Guilford Press; 2005.

[20] Stickney D, Hernandez G. Water bugs and dragonflies: Explaining death to young children. Cleveland, OH: Pilgrim Press; 1997.

[21] Strauss R, Thompson M. Tree of life: The incredible biodiversity of life on earth[Internet]. 2014. Available from: Kids Can Press@ http://www.kidscanpress.com/

[22] Lowenstein L. Creative interventions for bereaved children. Toronto: Champion Press; 2006.

[23] Miles MB, Huberman AM, Saldana J. Qualitative data analysis: A methods source book. (3rd ed.). Thousand Oaks, CA: Sage Publications; 2014. 